\title{
EXPERIMENTAL AND CFD ANALYSIS FOR EFFECT OF ABSORBER PLATE POSITION OF SOLAR WATER HEATER
}

\section{SUSHIL TIWARI \& DR. HIMANSHU AGRAWAL}

Research Scholar, Department of Mechanical Engineering, Government Engineering College, Jagadalpur, India

Associate Professor, Department of Mechanical Engineering, Government Engineering College, Jagadalpur, India

\begin{abstract}
With increasing energy demand worldwide, the need arises for alternate sources of energy which are abundantly available and have less or no carbon emission. Solar energy is available in abundance and free of cost. The tapping of this form of energy using solar water heater could fulfil our domestic and commercial water heating requirements. The current research investigates the feasibility of three different design configurations for solar water heater. These three designs are tube above plate, tube below plate and in-line tube plate arrangement. The CAD model of solar water heater is developed using Creo parametric design software and CFD analysis is conducted using ANSYS CFX software. Two variable standard k-epsilon turbulence model is used for analysis. The thermal flux considered for analysis are corresponding to 12 P.M. and 3 P.M solar intensity incident on collector plate of solar water heater. The comparative studies of three design configuration on the basis of efficiency, temperature rise is presented. The numerical results obtained from CFD analysis are in close agreement with experimental analysis.
\end{abstract}

KEYWORDS: Solar Water Heater, Solar Collector, CFD, ANSYS CFX

Received: Jun 10, 2020; Accepted: Jul 01, 2020; Published: Aug 20, 2020; Paper Id.: IJAERDDEC20204

\section{INTRODUCTION}

Solar water heating $(\mathrm{SWH})$ is the conversion of sunlight into heat for water heating using a solar thermal collector [1]. This conversion is achieved through three different energy transfer mechanisms i.e. conduction, convection and radiation. Solar water heater consists of collector, pump, tank, controller. The most important component is solar collector which captures and retains heat from the sun. The design of solar collectors determines the efficiency of solar water heater to a large extent. The pump circulates the heated fluid from tank to solar collector and vice versa [2].

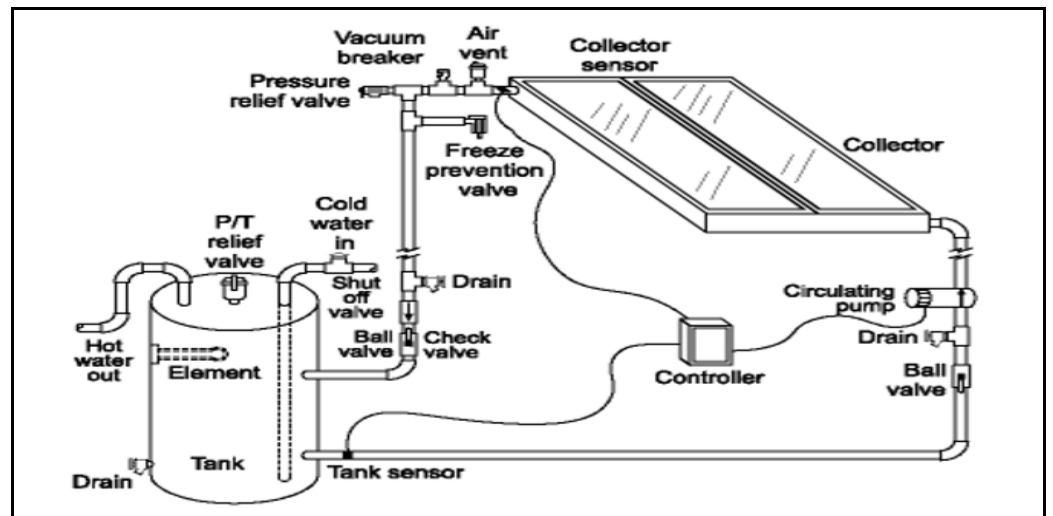

Figure 1: Solar Water Heating System Components [3]. 


\section{LITERATURE REVIEW}

K. Sivakumar et al [4] conducted experimental analysis on elliptical type solar collector. The parameter analysed was condenser length/evaporator length $(\mathrm{Lc} / \mathrm{Le})$ ratio under different mass flow rates. The findings have shown that $\mathrm{Lc} / \mathrm{Le}$ ratio of 0.1764 has highest efficiency.

Wattana Ratismith et al [5] conducted experimental analysis on parabolic trough collector and achieved 32\% collector efficiency with header temperature of $235^{\circ} \mathrm{C}$ of evacuated tube,which shows its feasibility for industrial applications.

P. Sivakumar et al [6] conducted experimental testing on flat plate collectors with zig-zag riser tubes. The findings have shown that with $\mathrm{Z}$ shape zig-zag tubes, efficiency is $62.90 \%$, which is nearly $3 \%$ higher than straight tubes.

K.K. Chong et al [7] conducted experimental testing on stationary V-trough solar water heater. The findings have shown that incident thermal flux increased to 1.8 times as compared to flat collector design and is easy to fabricate and cost effective, with high thermal efficiency.

\section{OBJECTIVES}

The current research investigates three different design configurations of tube and plate of solar heating system. Three different design configurations include tube over plate, tube under plate and lastly tube in line with plate. The investigations are conducted experimentally as well as numerically using ANSYS CFX software. The experimental and CFD analysis are conducted for 12PM and 3PM incident sunlight.

\section{RESEARCH METHODOLOGY}

The CAD modelling of solar water heater is developed using Creo 2.0 software which is a sketch based, parametric 3D modelling package. The CAD model comprises of glass, collector casing, copper tube and copper plate as shown in figure below.

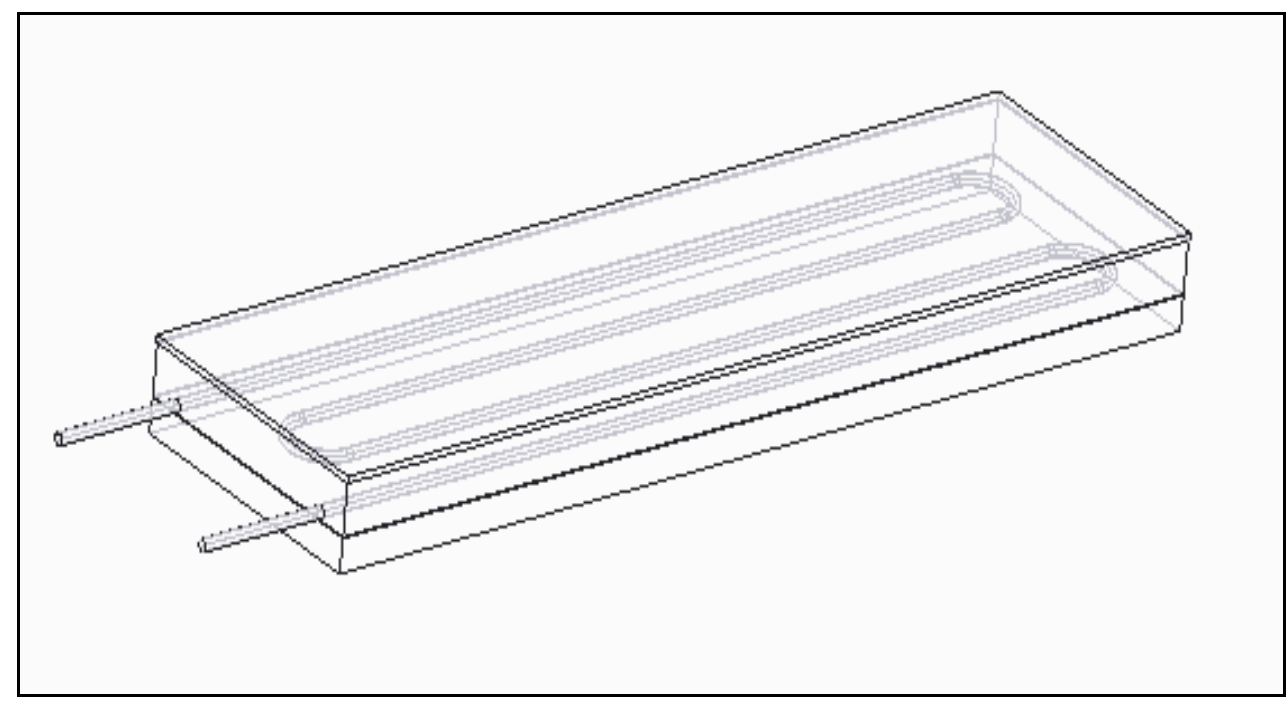

Figure 2: CAD Model of Solar Water Heater Collector (Plate Below Tube Configuration). 


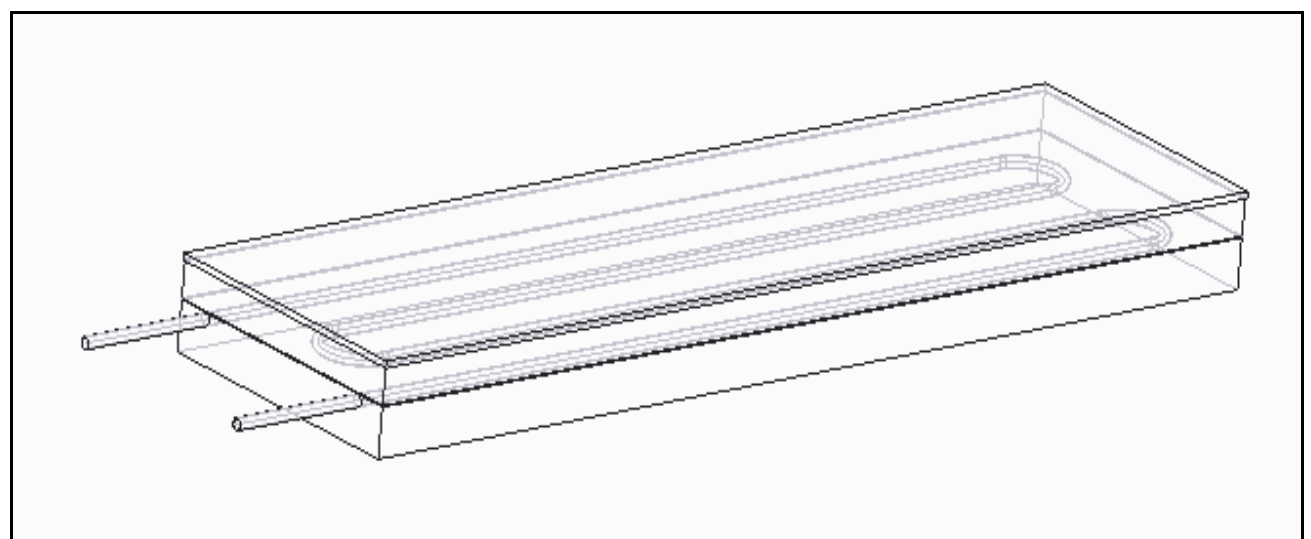

Figure 3: CAD Model of Solar Water Heater Collector (Plate Above Tube Configuration).

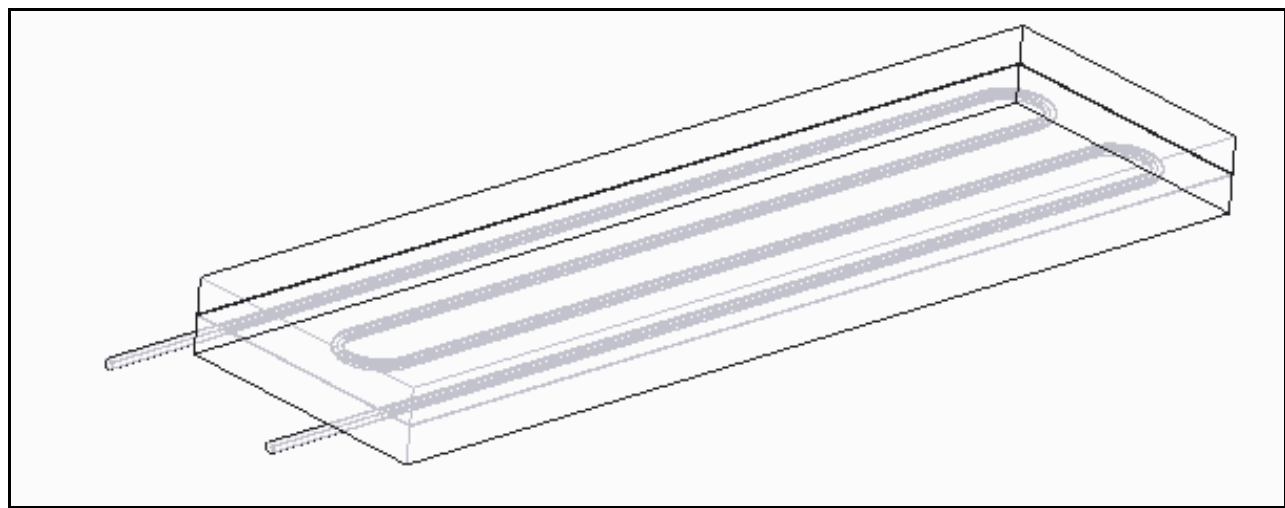

Figure 4: CAD Model of Solar Water Heater Collector (Plate Tube In-Line Configuration).

The CAD model developed in Creo 2.0 is imported in ANSYS design modeler. The CAD model is checked for geometric errors like hard edges, swivels etc as shown in figure below.

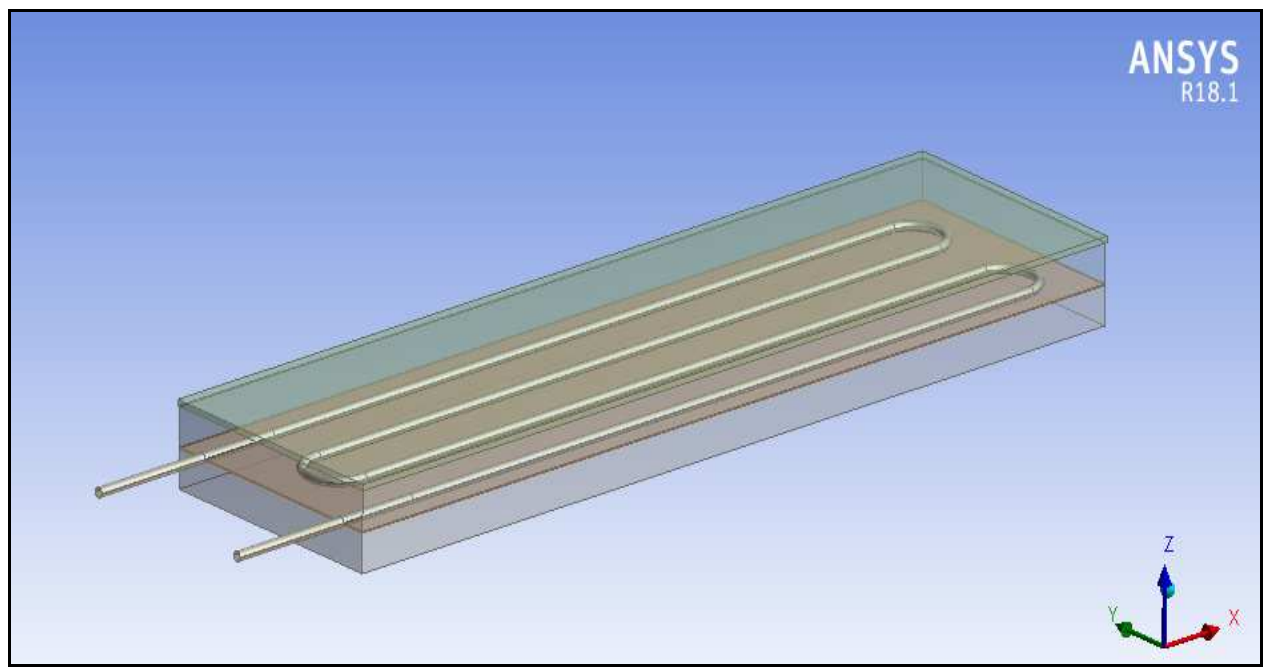

Figure 5: Imported CAD Model Of Solar Water Heater In ANSYS Design Modeller.

The naming of inlet and outlet boundaries, domain names of plates, tube and glass are defined. The defects are corrected here.The CAD model is meshed using tetrahedral elements and fine sizing with curvature effects on. The number 
of elements generated is 2863264 and number of nodes generated is 773447 . It consists of 4 nodes connected to each other by tetrahedral shape.

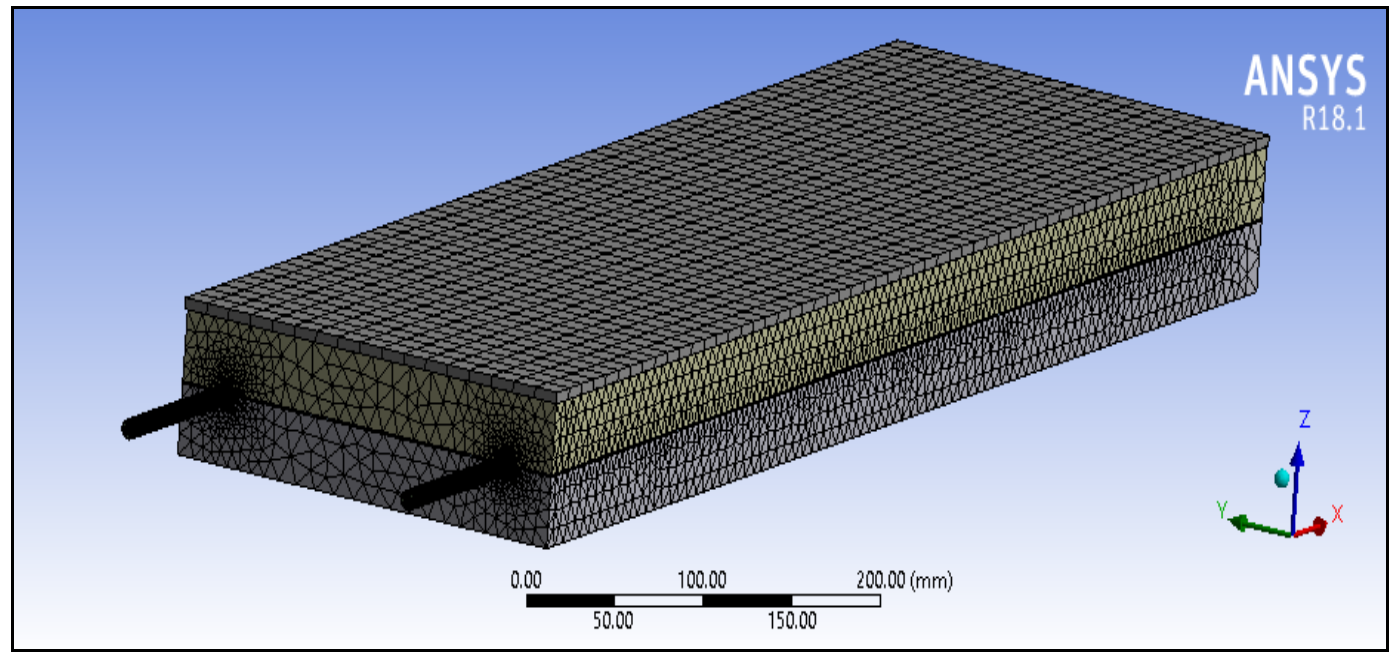

Figure 6: Meshing of Solar Water Heater.

The model is applied with appropriate loads, which includes defining radiation model and defining heat flux of $774,64 \mathrm{~W} / \mathrm{m}^{2}$ and $1037.80 \mathrm{~W} / \mathrm{m}^{2}$. The top part is defined with glass material. The rest of geometry is defined using air domain and water domain. The water inlet is defined at.003Kg/s and outlet pressure level is set to zero.

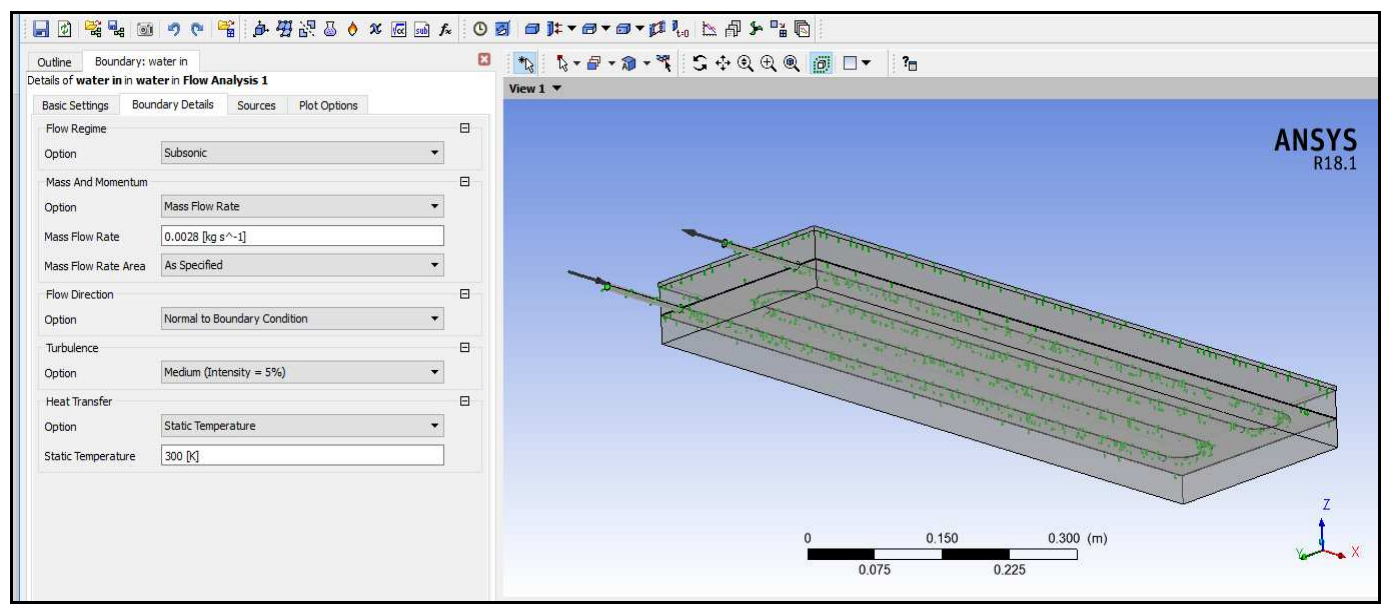

Figure 7: Loads and Boundary Conditions.

The next stage is the solution stage where software carries out matrix formulations, multiplications and inversions. Initially element stiffness matrix is formulated.The element stiffness matrix is assembled to form global stiffness matrix. When solver is set to run, the software calculates results at nodes and results are interpolated for entire element edge length.

\section{Efficiency Calculation}

There are 3 types of instantaneous efficiencies that are calculated for the procedure i.e. theoretical instantaneous efficiency, experimental instantaneous efficiency and instantaneous efficiency based on CFD analysis. 
And experimental instantaneous efficiency can be calculated by

$\eta_{i}=\frac{q_{u}}{A_{c} I_{T}}=\frac{m C_{p}\left(T_{f o}-T_{f i}\right)}{A_{c} I_{T}}(1)$

Theoretical instantaneous efficiency can be calculated by

$\eta_{i}=F_{R} \frac{A_{p}}{A_{c}}\left[(\tau \alpha)_{a v}-U_{l} \frac{\left(T_{f i}-T_{a}\right)}{I_{T}}\right]$ (2)

\section{RESULTS AND DISCUSSIONS}

The CFD analysis is conducted on solar water heater using ANSYS CFX software to determine temperature outlet and heat energy absorbed. The CFD analysis is conducted for time $12 \mathrm{Pm}$ and 3PM. The corresponding heat flux are $1037.80 \mathrm{~W} / \mathrm{m}^{2}$ and $774.64 \mathrm{~W} / \mathrm{m}^{2}$.

\section{CASE 1: Tube Over Plate Configuration}

The temperature plot and velocity plots are generated using CFD analysis as shown in figure 8 and figure 9 respectively.

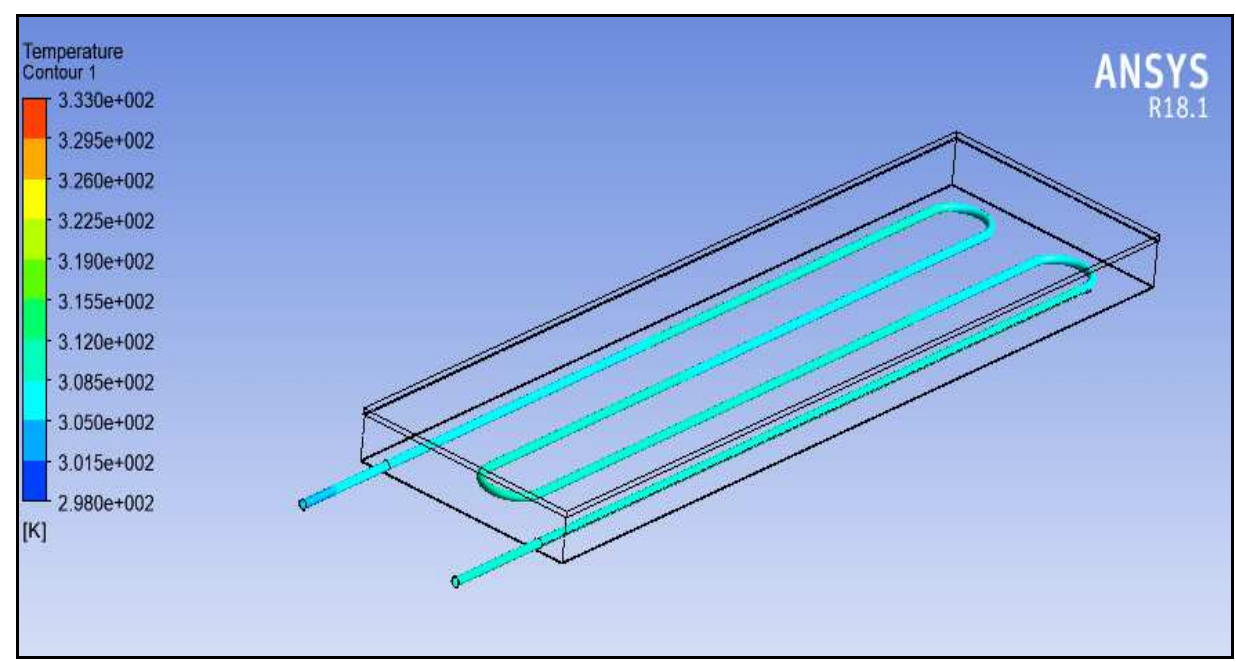

Figure 8: Temperature Plot of Solar Water Heater At 774.64W.

The temperature plot shown above shows that the maximum temperature of tube with magnitude of $333 \mathrm{~K}$ is at the mid portion of tube. The minimum temperature is near the inlet, which increases as we move towards the tube inside solar collector. 


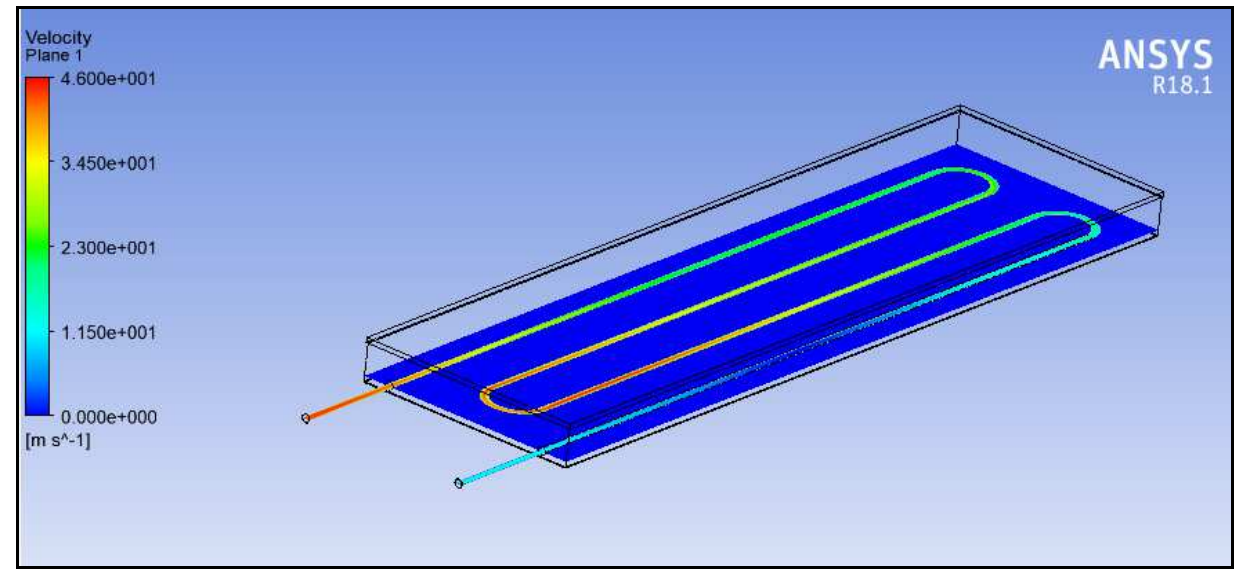

Figure 9: Velocity Plot of Solar Water Heater at 774.64W.

The velocity plot shown above predicts higher magnitude of velocity near inlet and at U-shape bend of pipe of magnitude $46 \mathrm{~m} / \mathrm{s}$ as shown red colour zone in figure 9 above. The other regions have lower velocity magnitude of $23 \mathrm{~m} / \mathrm{s}$ as shown by green colour plot.

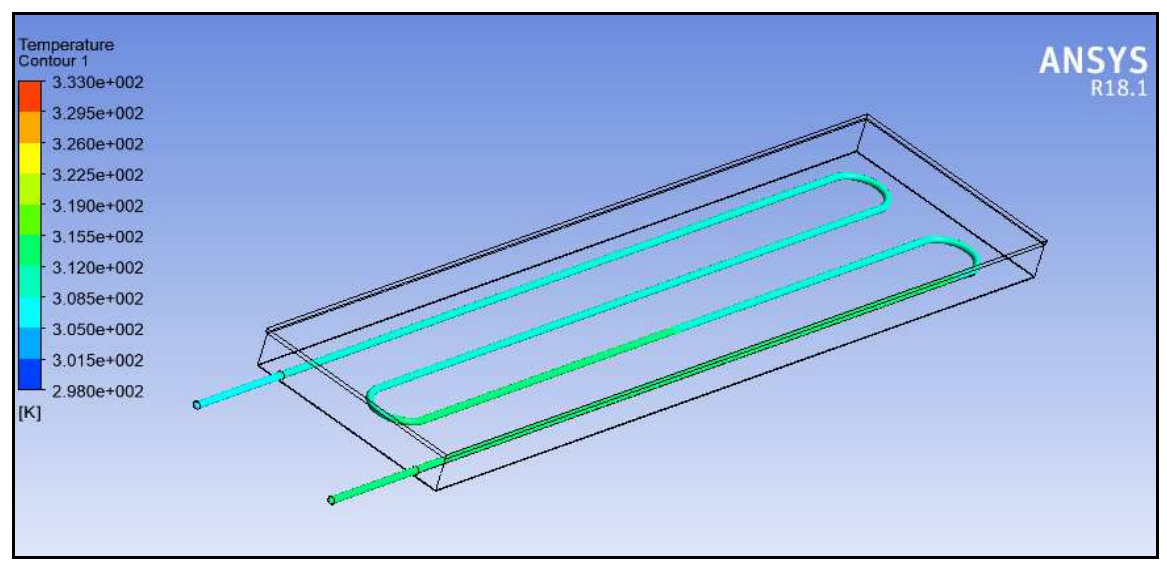

Figure 10: Temperature Plot of Solar Water Heater at 1037.80W.

The temperature plot shown above shows maximum temperature of tube with magnitude of $333 \mathrm{~K}$ at the outlet portion of tube. The minimum temperature is near inlet, which increases as we move towards the tube inside solar collector.

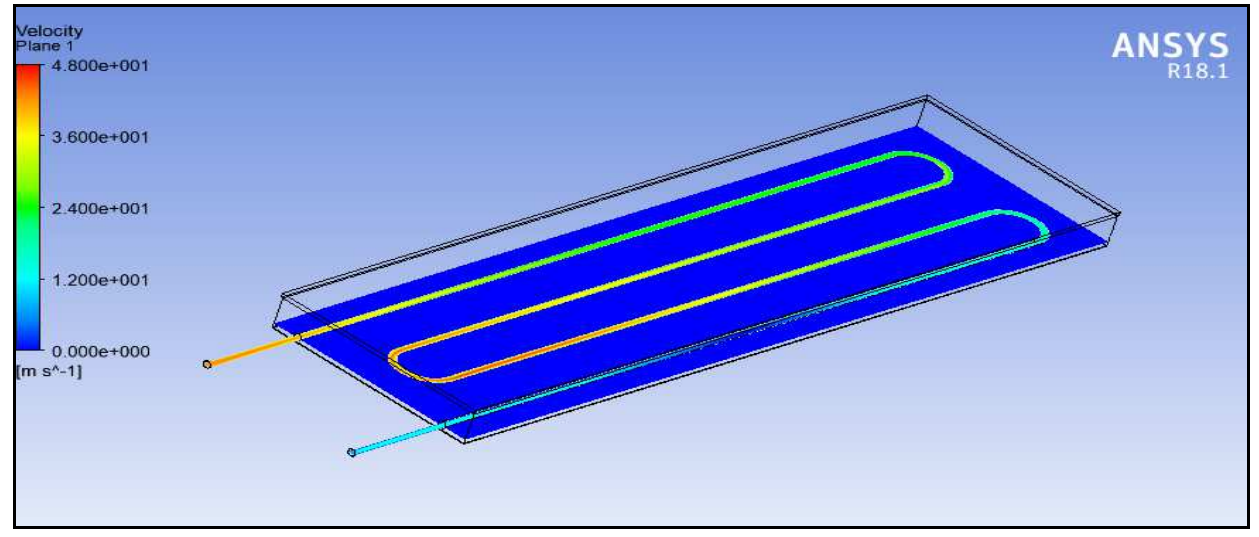

Figure 11: Velocity Plot of Solar Water Heater at 1037.80W. 
The velocity plot shown above predicts higher magnitude of velocity near inlet and at $U$ shape bend of pipe of magnitude $46 \mathrm{~m} / \mathrm{s}$ as shown red colour zone in figure 11 above. The other regions have lower velocity magnitude of $24 \mathrm{~m} / \mathrm{s}$ as shown by green colour plot.

\section{CASE 2: Tube below Plate Configuration}

The temperature plot and velocity plots are generated using CFD analysis as shown in figure 12 and figure 13 respectively.

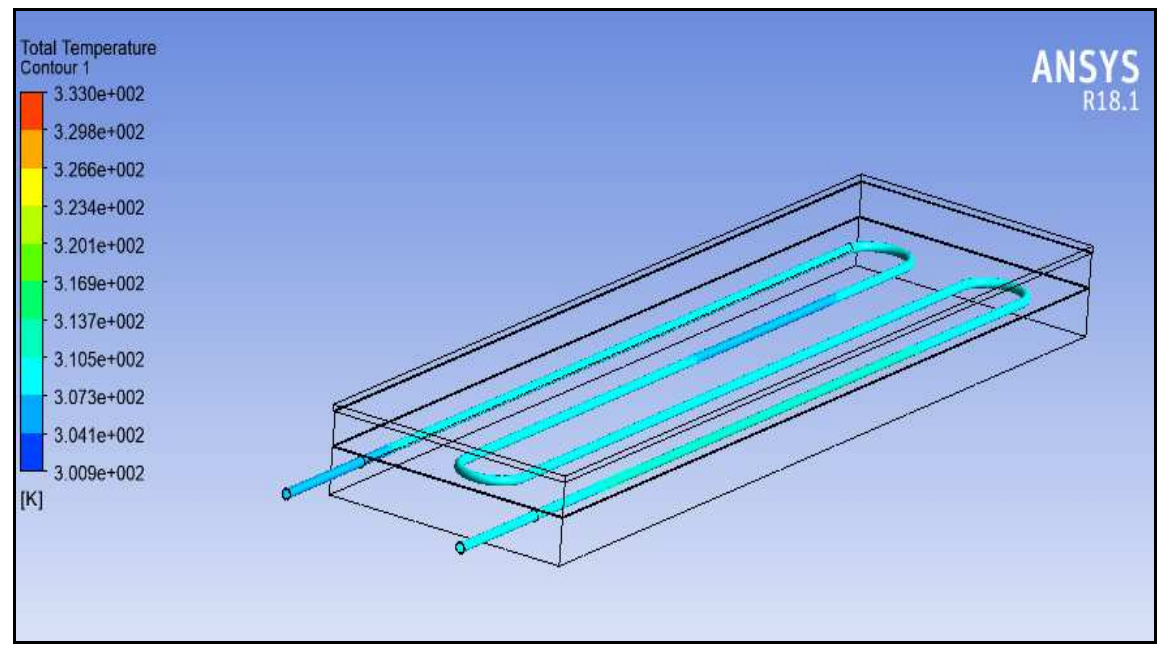

Figure 12: Temperature Plot of Solar Water Heater at 774.64W.

The temperature plot shown above shows maximum temperature of tube with magnitude of $333 \mathrm{~K}$ at the outlet portion of tube. The minimum temperature is near inlet, which increases as we move towards the tube inside solar collector.

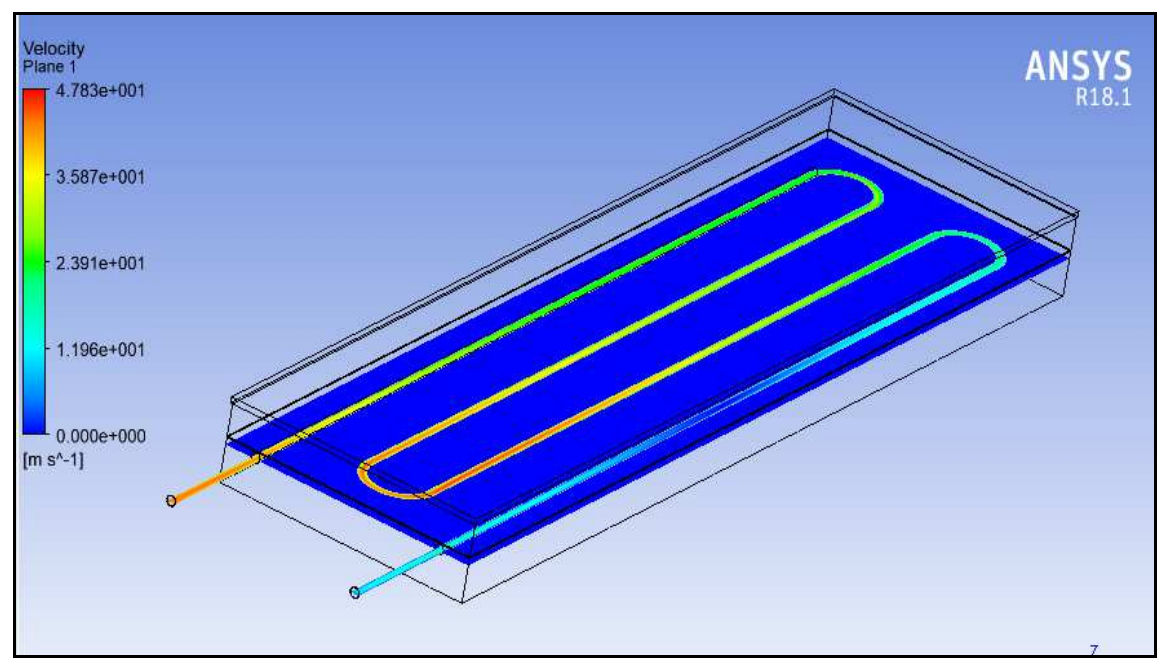

Figure 13: Velocity Plot of Solar Water Heater at 774.64W.

The velocity plot shown above predicts higher magnitude of velocity near inlet and at $U$ shape bend of pipe of magnitude $47.8 \mathrm{~m} / \mathrm{s}$ as shown red colour zone in figure 13 above. The other regions have lower velocity magnitude of $24 \mathrm{~m} / \mathrm{s}$ as shown by green colour plot. 


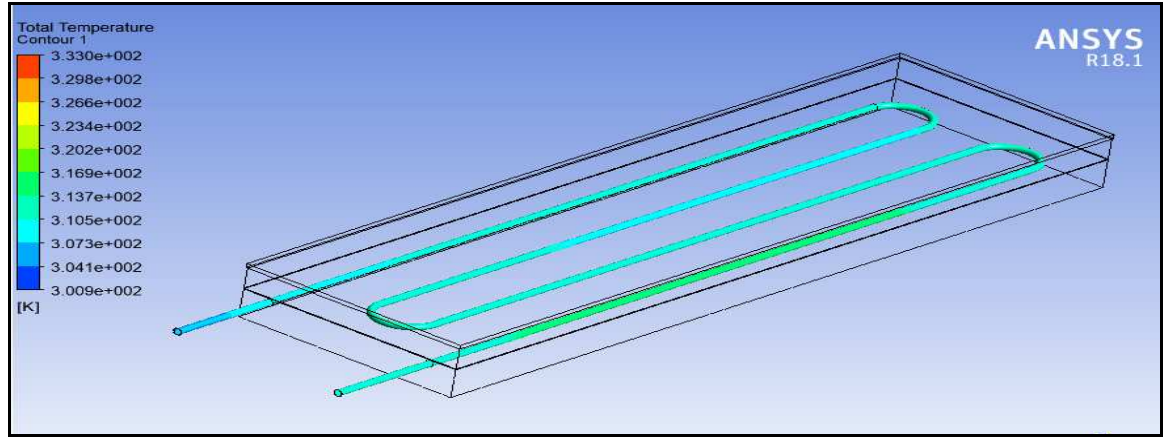

Figure 14: Temperature Plot of Solar Water Heater at 1037.80W.

The temperature plot shown above shows maximum temperature of tube with magnitude of $333 \mathrm{~K}$ at the outlet portion of tube. The minimum temperature is near inlet, which increases as we move towards the tube inside solar collector.

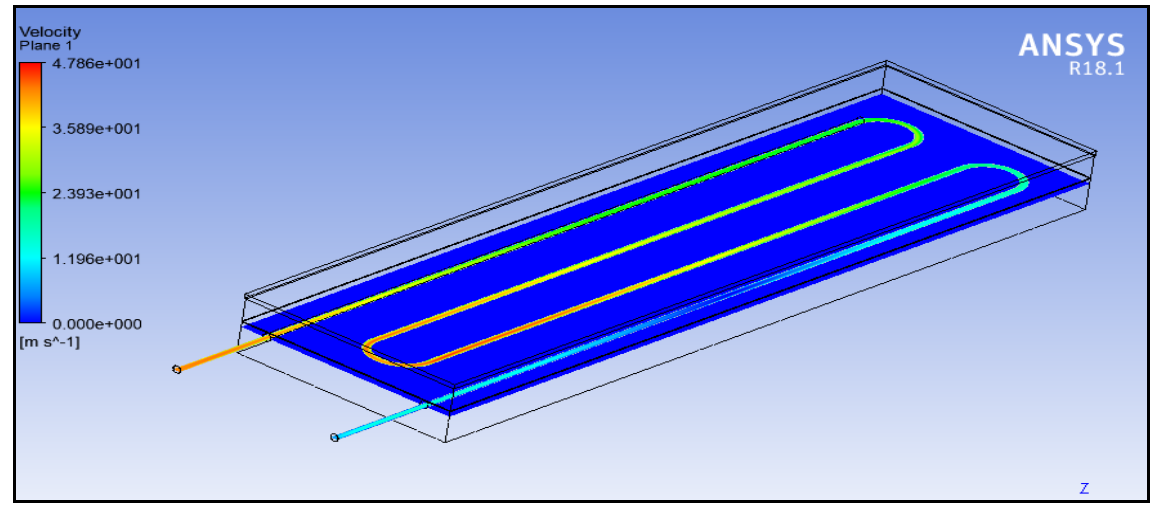

Figure 15: Velocity Plot of Solar Water Heater at 1037.80W.

The velocity plot shown above predicts higher magnitude of velocity near inlet and at $U$ shape bend of pipe of magnitude $47.8 \mathrm{~m} / \mathrm{s}$ as shown red colour zone in figure 15 above. The other regions have lower velocity magnitude of $24 \mathrm{~m} / \mathrm{s}$ as shown by green colour plot.

\section{CASE 3: Plate tube in-line Configuration}

The temperature plot and velocity plots are generated using CFD analysis as shown in figure 16 and figure 17 respectively.

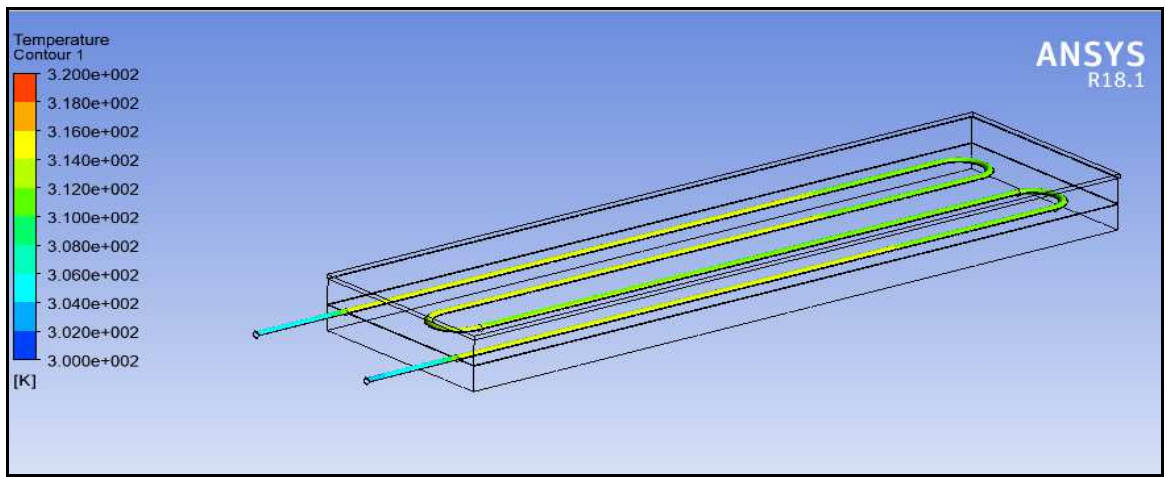

Figure 16: Temperature Plot of Solar Water Heater at 774.64W. 
The temperature plot shown above in figure 16 shows maximum temperature of tube with magnitude of $320 \mathrm{~K}$ at the outlet portion of tube. The minimum temperature is near inlet, which increases as we move towards the tube inside solar collector.

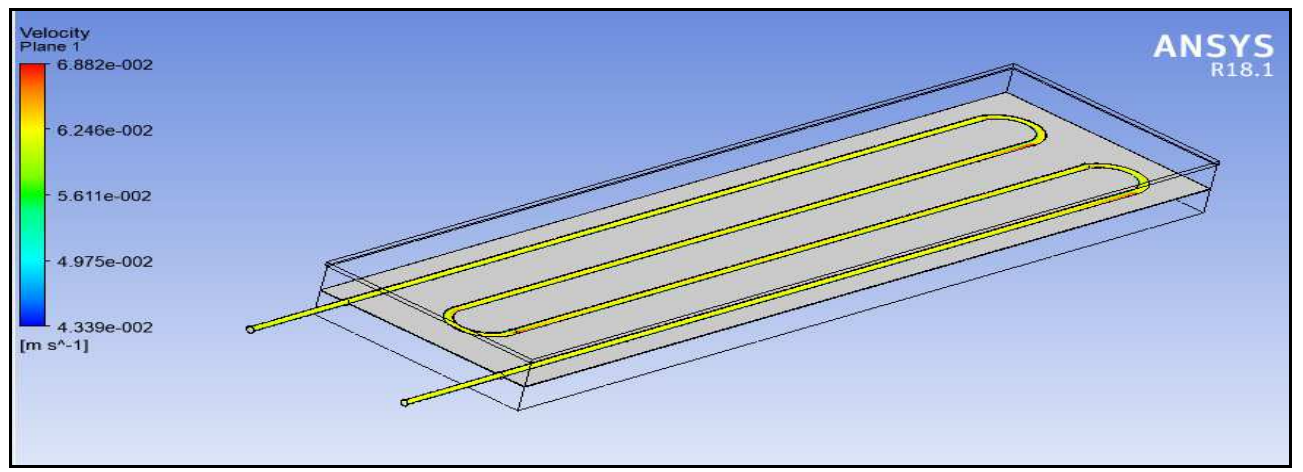

Figure 17: Velocity Plot of Solar Water Heater at 774.64W.

The velocity plot shown above in figure 17 predicts constant velocity profile along entire length. The velocity is. $0068 \mathrm{~m} / \mathrm{s}$, as shown by yellow colour zone.

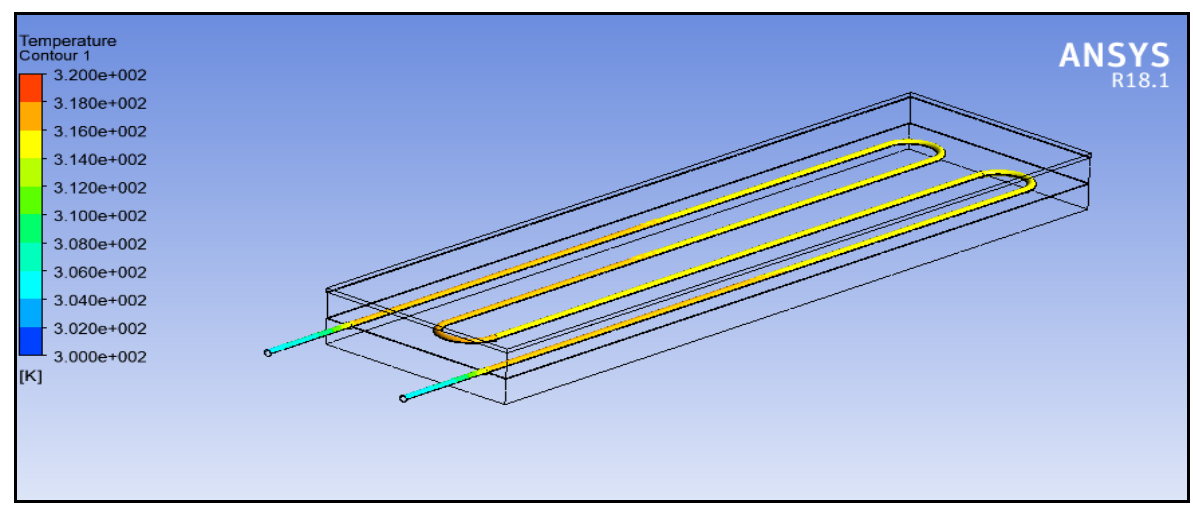

Figure 18: Temperature Plot of Solar Water Heater at 1037.80W.

The temperature plot shown above in figure 18shows maximum temperature of tube with magnitude of $320 \mathrm{~K}$ at the outlet portion of tube. The minimum temperature is near inlet, which increases as we move towards the tube inside solar collector.

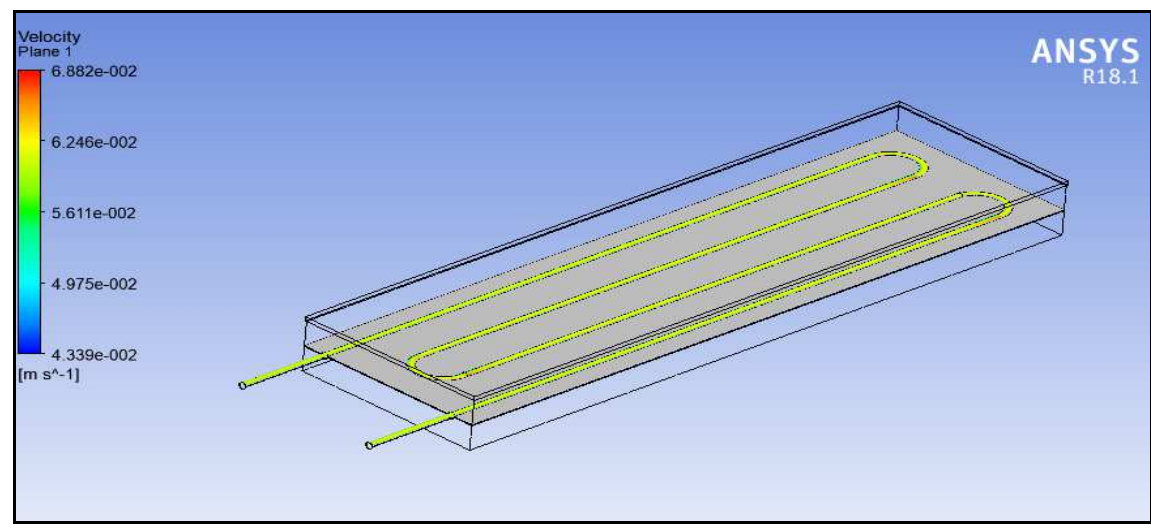

Figure 19: Velocity Plot of Solar Water Heater at 1037.80W. 
The velocity plot shown above predicts higher magnitude of velocity near inlet and at $U$ shape bend of pipe of magnitude. $068 \mathrm{~m} / \mathrm{s}$ as shown red colour zone in figure 19 above. The other regions have lower velocity magnitude of. $0056 \mathrm{~m} / \mathrm{s}$ as shown by green colour plot.

Table 1: Temperature Output Table

\begin{tabular}{|l|c|c|c|}
\hline & Tube above Plate & Tube below Plate & Tube Plate in-Line \\
\hline $\mathbf{T}_{\text {in }}$ (in K) & 300 & 300 & 300 \\
\hline $\mathbf{T}_{\text {out }}$ at 774.64W (in K) & 302.93 & 303.575 & 301.723 \\
\hline$\Delta \mathbf{T}_{\mathbf{7 7 4 . 6 4 W}}$ (in K) & 2.93 & 3.575 & 1.723 \\
\hline Heat absorbed (in J) & 34.28 & 41.82 & 20.16 \\
\hline $\mathbf{T}_{\text {out }}$ at 1037.80W (in K) & 304.45 & 304.389 & 302.171 \\
\hline$\Delta \mathbf{T}_{\mathbf{1 0 3 7 . 8 0}}$ (in K) & 4.45 & 4.38 & 2.171 \\
\hline Heat absorbed (in J) & 52.1 & 51.281 & 25.42 \\
\hline
\end{tabular}

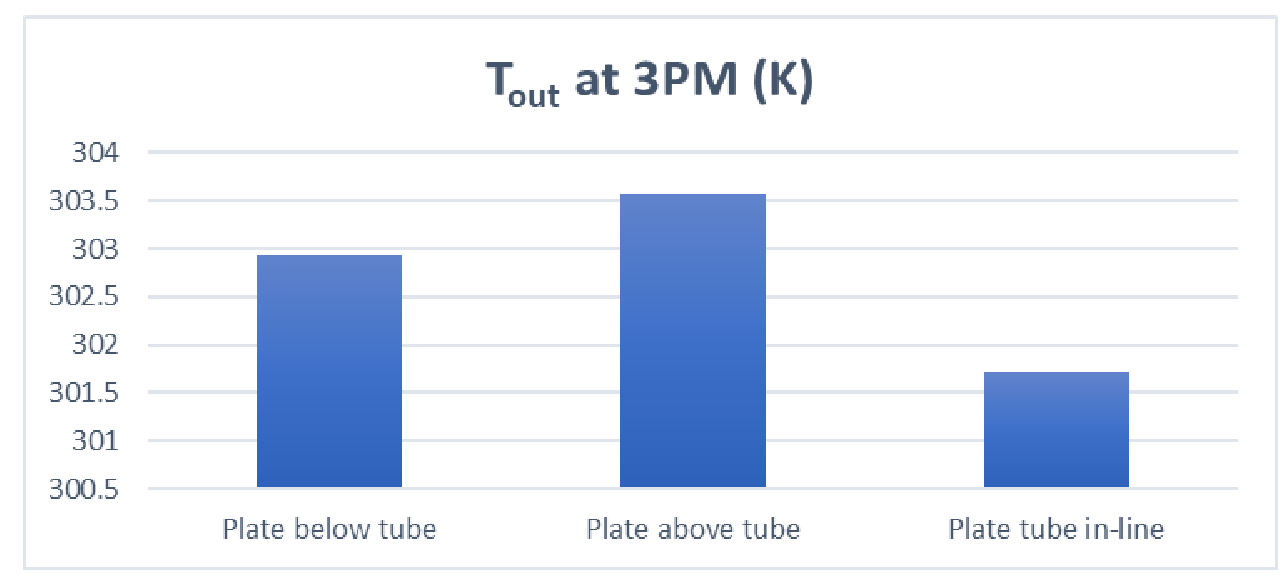

Figure 20: Outlet Temperature at 774.64 W Heat Flux.

As can be seen from graph in figure 20 above, for $774.64 \mathrm{~W}$ heat flux the maximum outlettemperature is observed for top plate design configuration followed by bottom plate and lowest outlet temperature is observed for in-line tube design.

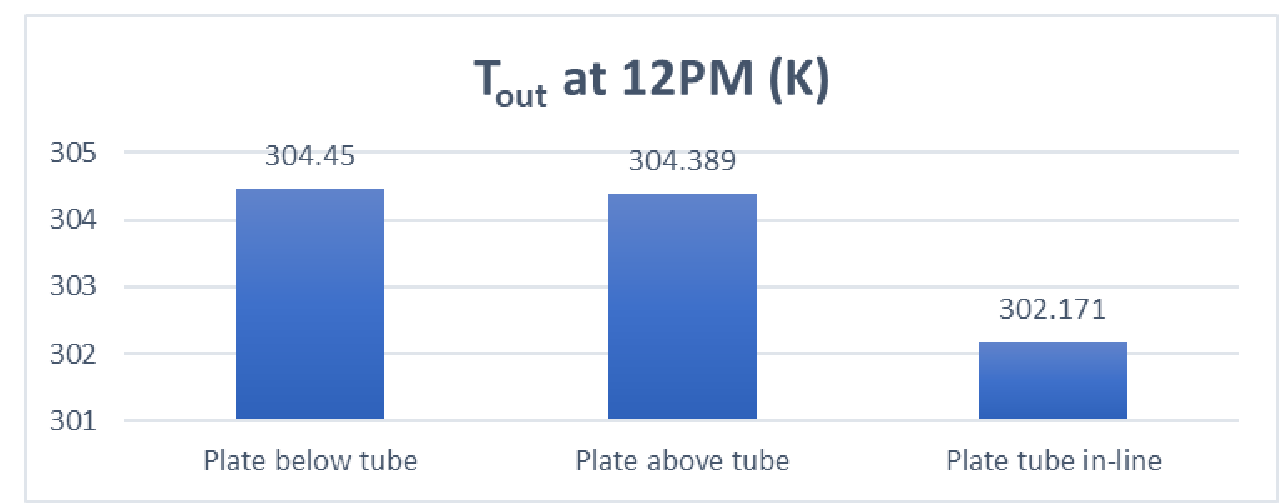

Figure 21: Outlet Temperature at 1037.80 W Heat Flux. 
Similarly, for 1037.80W heat flux, the maximum outlet temperature is observed for tube below plate design configuration followed by tube above plate and lowest outlet temperature is observed for in-line tube plate configuration as shown in figure 21 above.

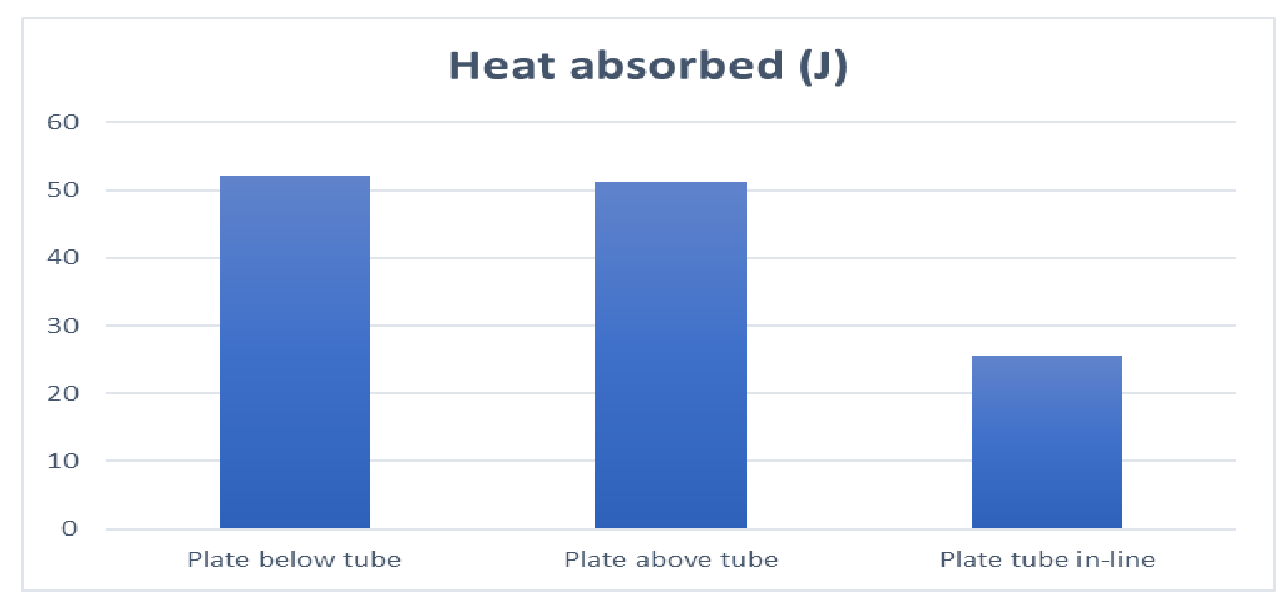

Figure 22: Heat Absorbed in Joules.

From figure 22 above, the maximum heat absorbed is by tube below plate design configuration followed by tube above plate configuration and lowest heat absorption is observed for in-line tube arrangement.

\section{CONCLUSIONS}

The experimental and CFD analysis is conducted on solar water heater with three different design configurations i.e. tube above plate configuration, tube below plate configuration and in-line tube configuration. The instantaneous efficiency, temperature plot and velocity plots are generated. The CFD (Computational Fluid Dynamics) has provided an effective tool is analysing heat transfer characteristics of solar water heater which also saved time and cost.

The detailed findings are as follows:

- K-epsilon turbulence model gave reasonable fluid flow predictions for all three design configurations of solar water heater. The turbulence model takes less computational time as compared to other models.

- The minimum efficiency of solar water heater is observed for inline tube configuration and maximum efficiency is observed for tube below plate configuration.

- The temperature rise observed is minimum for inline tube arrangement and maximum for tube below plate configuration.

- The maximum thermal efficiency for all the three design configurations is observed for $1037.80 \mathrm{~W}$ heat flux i.e. at 3 PM afternoon time.

- The practical efficiency is lower than theoretical efficiency for all the three design configurations of solar water heater.

- The numerical results obtained from CFD analysis shows nearly $20 \%$ variation of results as compared to practical efficiency. This is due to meshing characteristics. 


\section{REFERENCES}

1. C. Marken (2009). "Solar collectors: Behind the glass". Home Power. 133: 70-76.

2. Norton, Brian (2013). Harnessing Solar Heat. Springer.

3. Pittala, Suresh, and T. Diriba. "Computational Fluid Dynamics Analysis of Impeller Design For A Pump." International Journal of Mechanical Engineering (IJME) 5.4.

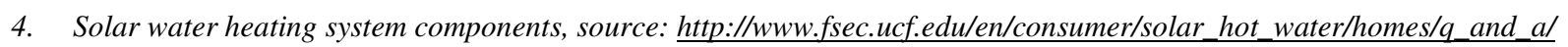

5. K. Sivakumar, N. Krishna Mohan and B. Sivaraman -Performance analysis of elliptical heat pipe solar collector\| Indian Journal of Science and Technology.

6. Reddy, P. RAVINDER, and M. Saikiran. "Aerodynamic Analysis of Return Channel Vanes in Centrifugal Compressors." International Journal of Mechanical Engineering (IJME), 5 (1), 7382 (2016).

7. Wattana Ratismith, -A Novel Non-Tracking Solar Collector for High Temperature Application.ll, proceedings of ecos 2012 the 25th international conference on efficiency, cost, optimization, simulation and environmental impact of energy systems June 2629, 2012, Perugia, Italy.

8. Roy, Samanwita. "COMPARATIVE FLOW ANALYSIS OF NACA S6061 AND NACA 4415 AEROFOIL BY COMPUTATIONAL FLUID DYNAMICS."International Journal of Mechanical Engineering (IJME) ISSN (P): 2319-2240; ISSN (E): 2319-2259 Vol. 7, Issue 2, Feb-Mar 2018; 9-18

9. P. Sivakumar1, W. Christraj, M. Sridharan1 and N. Jayamalathi1,„Performance Improvement Study Of Solar Water Heating Systeml, ARPN Journal of Engineering and Applied Sciences, VOL. 7, NO. 1, January 2012, ISSN 1819-6608.

10. Roy, Samanwita. "COMPARATIVE FLOW ANALYSIS OF NACA S6061 AND NACA 4415 AEROFOIL BY COMPUTATIONAL FLUID DYNAMICS."International Journal of Mechanical Engineering (IJME) ISSN (P): 2319-2240; ISSN (E): 2319-2259 Vol. 7, Issue 2, Feb-Mar 2018; 9-18

11. K.K. Chong, K.G. Chay, K.H. Chin, -Study of a solar water heater using stationary V-trough collectorl, Renewable Energy 39 (2012) 207-215. 